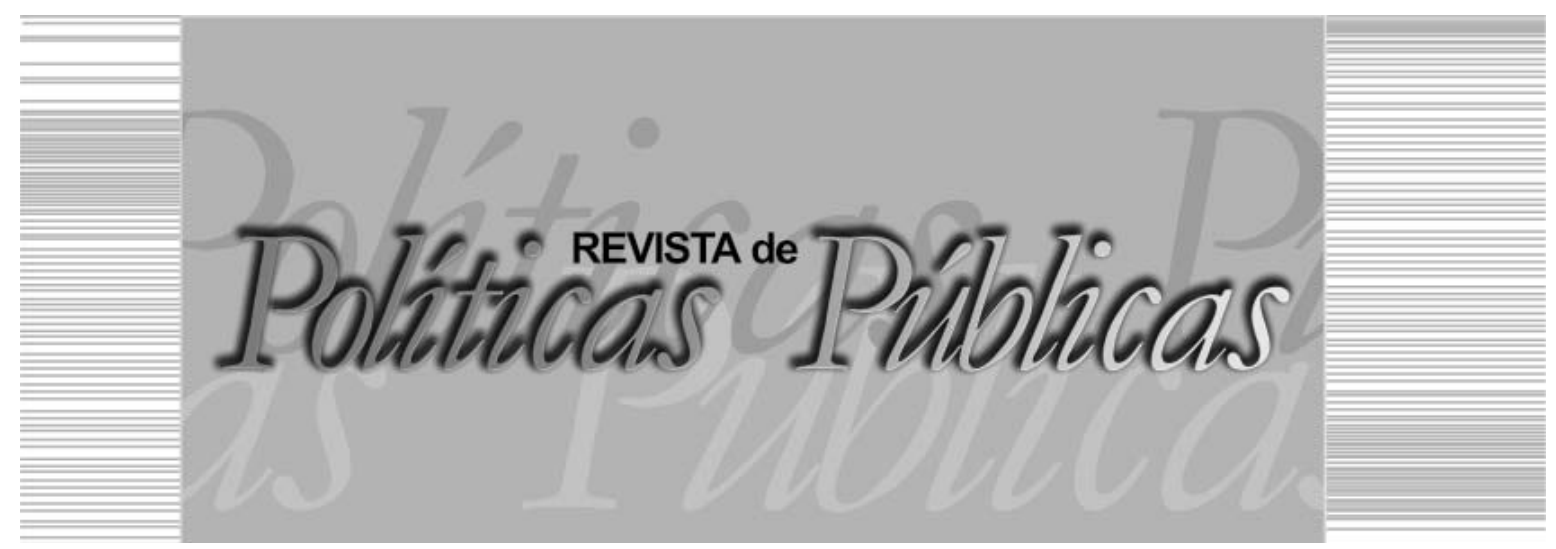

\title{
TRAJETORIA DA REGULAMENTAÇÃO DOS BENEFICIOS EVENTUAIS: da Previdência ao SUAS
}

\author{
Marielle Anne Morais Soares ${ }^{1}$ \\ Prefeitura Municipal de Tianguá - CE \\ André Menezes Gonçalves ${ }^{2}$ \\ Universidade Federal de Campina Grande (UFCG)
}

\section{Resumo}

O objetivo deste artigo é apresentar o histórico de regulamentação dos Benefícios Eventuais passando da Previdência até sua atual configuração como integrante do Sistema Único de Assistência Social. Por meio deste panorama entendemos o processo de construção do SUAS e dos benefícios eventuais através de uma conturbada trajetória, passando de auxílio maternidade e funeral, destinados somente aos contribuintes da Previdência, para benefícios assistenciais dentro da LOAS, ampliando seu acesso e as modalidades de provisão. A ausência de regulamentação pelos municípios trouxe um atraso de mais de 10 anos para reconhecê-los como direito socioassistencial, o que foi fomentado após as iniciativas do CNAS e do MDS. O seu reconhecimento como provisão suplementar e provisória se dá com a Lei $\mathrm{n}^{\circ} 12.435 / 2011$, que altera o texto da LOAS e traz grandes inovações para o SUAS e para os benefícios.

Palavras-chave: Assistência Social, benefícios eventuais, Sistema Único de Assistência Social.

\footnotetext{
Assistente Social. Especialista em Serviço Social, Seguridade Social e Legislação. Previdenciária (Ratio). Servidora Pública Efetiva da Prefeitura Municipal de Tianguá - CE. E-mail: mariellemorais@hotmail.com | Prefeitura Municipal de Tianguá - CE |Av. Moisés Moita, 785, Planalto | CEP: 62.320-000

2 Assistente Social. Mestre em Planejamento e Políticas Públicas. Professor do Curso de Serviço Social da Universidade Federal de Campina Grande (UFCG). E-mail: andremg@uol.com.br | Universidade Federal de Campina Grande (UFCG) | Centro de Ciências Jurídicas e Sociais (CCJS) | BR 230, s/n, Sousa, PB | CEP: 58.800-000
} 
REGULATION'S TRAJECTORY OF POTENTIAL BENEFITS: from Social Security to Unified Social Assistance System

\begin{abstract}
The objective of this paper is to present the regulatory history of Potential Benefits through the social security until the current configuration as a member of the Unified Social Assistance System. Through the history of social assistance we understand the Unified Social Assistance System construction process for Social Assistance and therefore the possible benefits through a troubled history, from aid maternity and funeral, intended only to taxpayers of Welfare for assistance benefits in the LOAS, expanding its access and the modalities of provision. The absence of regulation by municipalities brought a delay of more than 10 years to recognize them as social assistance law, which was fostered after the CNAS initiatives and MDS by conducting national studies and enactment of Resolution. The recognition as supplementary and temporary profession is given to Law $\mathrm{n}^{\circ}$. 12.435/2011, amending the text of the LOAS and brings great innovations for Unified Social Assistance System and for benefits.

Key words: Social Assistance, possible benefits, Unified Social Assistance System.
\end{abstract}

\title{
1 INTRODUÇÃO
}

A política de assistência social, notadamente pós emergência de sua regulamentação com a Lei ${ }^{\circ} 8.742$, de 7 de dezembro de 1993 (Lei Orgânica de Assistência Social [LOAS]) e nos marcos do Sistema Único de Assistência Social (SUAS), fortaleceu-se em seu caráter protetivo, organizando-se e materializando-se em programas, projetos, serviços e benefícios socioassistenciais. O debate aqui apresentado versa sobre os benefícios eventuais, constituintes da Proteção Social Básica (PSB), direcionados a famílias que vivenciam situações diversas de pobreza e de miséria.

Historicamente esses benefícios configuraram-se como provisões que transitam entre a resposta imediata de determinadas necessidades, como acesso a alimentos, entre a tutela, a benesse e a troca de favor (especialmente em períodos eleitorais), e, também, na perspectiva dos direitos, quando garantem, minimamente, a segurança de renda. Seu caráter é objetivado quando do acesso a bens materiais, como gêneros alimentícios, utensílios, objetos etc., ou em pecúnia. Isso numa perspectiva contemporânea prevista no âmbito do art. 22 da LOAS. Mas as primeiras ações em nosso país dos be- 
TRAJETORIA DA REGULAMENTAÇÃO DOS BENEFÍCIOS EVENTUAIS:

da previdência ao $S U A S$

nefícios eventuais datam do ano de 1954 , pelo Decreto $\mathrm{n}^{\circ} 35.448$, de 1 de maio, vinculados à política previdenciária, aos contribuintes.

Como dito, os benefícios eventuais atualmente integram a PSB no âmbito do SUAS, compreendidos como provisões suplementares e provisórias em virtude de nascimento, morte, situações de vulnerabilidade temporária e de calamidade pública, como preconiza a LOAS. (BRASIL, 1993).

O presente estudo tem o objetivo de conhecer a atual configuração e regulamentação dos benefícios eventuais da política de assistência social tendo em vista seu reconhecimento numa perspectiva de direito. Pretende-se, portanto, analisar seu processo de regulamentação desde a sua integração à política de previdência até seu reconhecimento dentro do sistema descentralizado, participativo e de gestão da assistência social.

Em termos de argumentação, primeiro realizamos uma breve história da política de assistência social, mas optamos em aprofundar o debate em termos mais contemporâneos - a emergência do SUAS e sua relação com os benefícios eventuais. Apontamos algumas questões no âmbito do debate acerca da vulnerabilidade social e dos mínimos sociais para situarmos a atual configuração dos benefícios eventuais.

Mesmo com enormes desafios no âmbito da gestão desses benefícios, acreditamos que os mesmos assumem deveras importância no âmbito do atendimento das necessidades de várias famílias que transitam os territórios dos Centros de Referência da Assistência Social (CRAS) demandando respostas às suas necessidades sociais.

\section{BREVES CONSIDERAÇÕES SOBRE AS POLÍTICAS SOCIAIS}

A assistência social tem sua história de consolidação como política pública permeada de avanços e retrocessos, mesmo após seu reconhecimento enquanto direito pós o período 1988-1993. Das ações de iniciativa privada e religiosa, tendo como bojo a noção de caridade e filantropia, ou nas ações do Estado para responder às demandas da classe trabalhadora, a assistência social se formata a partir das demandas decorrentes do desenvolvimento do modo de produção capitalista e da produção e reprodução da pobreza, da miséria e das desigualdades típicas desse padrão de acumulação. 
Nesse sentido, faremos uma breve discussão da história dessa política pública através de suas primeiras manifestações no mundo e no Brasil, até sua atual configuração: de direito constitucional e organizada a partir de um sistema hierarquizado, descentralizado e por níveis de proteção.

Não há precisão bibliográfica quanto ao período específico do surgimento das primeiras iniciativas identificadas como políticas sociais. No entanto, há o reconhecimento de seu fenômeno enquanto processo gestado a partir do movimento da classe trabalhadora, do incremento no capitalismo com a Revolução Industrial ${ }^{3}$ e do desenvolvimento da intervenção estatal. O Estado, especialmente na Europa, no período que vai de meados do Século XIX até a terceira década do Século XX, foi marcado profundamente pelas ideias liberais, especialmente pelas teses de Smith, em que seu papel interventivo deveria ser mínimo, resumindo-se a fornecer as bases legais para o funcionamento do mercado. (BEHRING; BOSCHETTI, 2011).

De um lado, havia iniciativas pontuais de caridade privada e da filantropia religiosa, identificadas como protoformas de políticas sociais, uma vez que assumiam algumas responsabilidades de atendimento às necessidades da população e, do outro, havia as legislações seminais ou fabris que dispunham pioneiramente sobre o trabalho, contendo mais repressão do que garantia de direitos. (BEHRING; BOSCHETTI, 2011).

Dentre essas legislações, as mais conhecidas foram as inglesas Lei dos Pobres, de 1531; Lei do Domicilio, de 1662; e a Nova Lei dos Pobres, datada de 1834. Apresentavam caráter coercitivo, punitivo e repressor destinado aos pobres, sejam trabalhadores ou não trabalhadores. Ao invés de proteger aqueles que vendiam sua força de trabalho, essas legislações obrigavam àqueles que dependiam da prática laboral a se submeterem a qualquer infortúnio em troca de remuneração, vetando a existência da mendicância aos chamados pobres aptos ao trabalho (ou pobres não merecedores da assistência filantrópica, religiosa ou do Estado). Nesse sentido de forçar o exercício do trabalho, foram criadas as workhouses (casas de trabalho), exigindo dos pobres contrapartida à assistência recebida de auxílios

\footnotetext{
Processo de transição do sistema produção da manufatura, ou acumulação primitiva do capital, para o capitalismo que tem o tear e máquina a vapor como sua base técnica. (SANTOS, 2012)
} 
TRAJETORIA DA REGULAMENTAÇÃO DOS BENEFÍCIOS EVENTUAIS:

da previdência ao $S U A S$

mínimos, como a alimentação, especialmente pela exploração de suas práticas laborativas. (BEHRING; BOSCHETTI, 2011).

Sobre esse modelo coercitivo do trabalho, exigia-se compensação para o recebimento de auxílios, segundo Pereira (2011, p. 116):

No século XIX, a cobrança da contrapartida, ou do reverso da as-
sistência, era tão forte que chegava às raias da insensatez. Exigia-
-se, por exemplo, na Europa, que famintos construíssem torres des-
necessárias para justificar o recebimento de alimentos (geralmente
batatas) em tempos de crise. Se a fome persistisse, a cobrança
mudava de orientação, mas não de perversidade: exigia-se que os
famintos destruíssem a torre levantada para que pudessem fazer jus
à nova concessão de alimentos.

As práticas assistenciais advindas do Estado ou da iniciativa privada-religiosa, de um modo geral, requeriam algum tipo de contrapartida de seus assistidos. A lógica liberal não concebia que o trabalhador recebesse qualquer benefício que não fosse decorrente do dispêndio da força de trabalho. Ele deveria se manter através de seu próprio esforço e a qualquer custo. Somente aos incapacitados (crianças carentes, pessoas idosas e inválidos, os chamados pobres merecedores) era admitido o usufruto das ações assistenciais, arraigadas de valores religiosos e morais.

Ainda na Inglaterra, a Lei de Speenhamland, de 1795, introduziu uma inovação econômica e social ao reconhecer o direito a um mínimo de subsistência aos trabalhadores, estabelecendo o pagamento de um abono em pecúnia calculado a partir do valor do pão e do número de filhos. (BEHRING; BOSCHETTI, 2011). Além disso, não excluía os desempregados e exigia em contrapartida apenas a fixação do trabalhador, pois tinha como princípio a sua sustentação e de sua família através da paroquia local. Para Pereira (2011), com essa lei foi estabelecido o direito (natural) de viver. Contudo, foi considerada um ultraje à lógica liberal e ao predomínio do capitalismo e durou apenas 39 anos após ser revisada pela Nova Lei dos Pobres, em 1834, que aboliu qualquer outra forma de garantia de renda que não fosse através do trabalho.

Devido ao fato de garantir condições mínimas de sobrevivência ao complementar os baixos salários, essa lei impedia o livre mercado da força de trabalho tão necessário para emergência de um proletariado industrial e móvel. Com a revisão da Speenhamland, as 
ações assistenciais voltam a incorrer sobre discurso do Estado mínimo, de perspectiva liberal e de mínima intervenção sua nas relações econômicas e sociais.

O trabalho passa cada vez mais a ser considerado como atividade natural ao homem e, por conseguinte, o Estado se recolhe em suas ações de atendimento às necessidades básicas dos trabalhadores. A política social será um instrumento importante para produzir e reproduzir a mais valiosa mercadoria, a força de trabalho, tão útil e necessária ao desenvolvimento do modo de produção capitalista. E é nessa relação que as políticas sociais irão se formatar a fim de atender e/ou enfrentar os desdobramentos da questão social, cuja fundamentação decorre das relações de exploração do trabalho em virtude do capital.

A questão social não é senão as expressões do processo de formação e desenvolvimento da classe operária e de seu ingresso no cenário político da sociedade, exigindo seu reconhecimento como classe por parte do empresariado e do Estado. É a manifestação, no cotidiano da vida social, da contradição entre o proletariado e a burguesia, a qual passa a exigir outros tipos de intervenção, mais além da caridade e repressão. (IAMAMOTO; CARVALHO, 2000, p. 77).

A gênese, portanto, da questão social, está na maneira como os homens se organizaram para requerer respostas do Estado para suas condições de vida que eram - e ainda são - afetadas sobremaneira pela forma exploratória da produção da riqueza. O Estado deverá legislar para além de regulações fabris, pois a vida humana também se reproduz fora do chão das fábricas. As políticas sociais, nesse sentido, formatam-se a partir da conjuntura social, econômica, política e cultural de um dado momento histórico. Noutras palavras: são construções sócio-históricas advinda da correlação de forças das classes sociais, mediadas pelo Estado.

Em razão da maior organização da classe trabalhadora para reconhecimento de seus direitos, o Estado europeu, no final do Século XIX, emerge com políticas sociais mais significativas, superando as legislações seminais e as ações privadas crivadas de caridade. Justamente nesse período é que serão criadas as primeiras caixas de poupança e previdência como estratégia de garantir a subsistência dos trabalhadores nos momentos de greve ou de interrupção das atividades laborativas. Com o objetivo de desmobilizar as lutas sociais, tomam forma os primeiros modelos de seguro social de iniciativa 
governamental, como ocorreu na Alemanha, em 1883, no governo de Bismarck ${ }^{4}$, o que vai influenciar a criação de modelos de seguridade social em boa parte do mundo sob a lógica do seguro social. Isto é, que precede de contribuição dos trabalhadores para seu usufruto e/ou de seus dependentes. (BEHRING; BOSCHETTI, 2011).

A mudança de conjuntura provocada pela forte mobilização da classe trabalhadora e o processo de concentração e monopolização do capital foram aos poucos ruindo as bases de sustentação dos argumentos liberais. Estes dois processos socioeconômicos fizeram com que o Estado passasse do viés liberal para um viés mais social a fim de garantir a permanência de poder nas mãos da burguesia. Portanto, se fazia necessário reconhecer os direitos de cidadania e torná-los cada vez mais extensivos às necessidades da classe trabalhadora.

No Século XX, foi com a crise de 1929 e a II Guerra Mundial que a burguesia reconheceu os limites do mercado e a necessidade interventora-reguladora do Estado nas crises cíclicas do capital. A grande depressão foi uma das maiores crises já vivenciada pelo capitalismo em decorrência do seu próprio desenvolvimento baseado nos ideais liberais, exigindo mudanças quanto à percepção do papel do Estado. Preocupados em sair da crise, há o reconhecimento da necessidade da intervenção estatal para seu enfrentamento e as políticas sociais são desenvolvidas e ampliadas fortemente como ferramenta auxiliar desse processo.

As políticas sociais estarão baseadas nas ideias de Keynes que defendia intervenção estatal a partir de saídas democráticas da crise (BEHRING; BOSCHETTI, 2011), como a geração de empregos através de serviços públicos, o aumento da renda e do consumo, e fortes investimentos de grandes volumes de recursos públicos para o capital. Mas o incremento das políticas sociais não se atém ao Estado keynesiano. Em 1943, na Inglaterra, foi publicado o Plano Beveridgeque propõe uma nova lógica de organização das políticas

\footnotetext{
O modelo bismarckiano de proteção social, que surge entre os anos de 1883 e 1889 na Prússia (atual Alemanha), simboliza o nascimento da chamada previdência social. Foi um conjunto de respostas do Governo do Chanceler Otto von Bismarckàs greves e pressões dos trabalhadores e se baseia no sistema de seguros sociais. O financiamento desse sistema de proteção é feito através da contribuição direta de empregados e empregadores. A gestão é compartilhada (Estado e contribuintes) e segue o modelo de caixas previdenciárias: modelo contributivo que garante o direito a prestações reparadoras ao verificar-se um dado evento danoso, antes que este possa determinar o estado de indigência ou privação do segurado. (BOSCHETTI, 2009).
} 
sociais a partir da crítica aos modelos de seguro social bismarckiano. O modelo inglês se difere do alemão por trazer, estrategicamente, a lógica do acesso universal às políticas e aos direitos sociais que até então estavam focalizadas em algumas categorias trabalhistas. Esta lógica vai caracterizar o Welfare State (Estado de Bem-Estar Social) que tem como princípios:

1) responsabilidade estatal na manutenção das condições de vida dos cidadãos, por meio de um conjunto de ações de três direções: regulação da economia de mercado a fim de manter elevado nível de emprego; prestação pública de serviços sociais universais, como educação, segurança social, assistência médica e habitação; e um conjunto de serviços sociais pessoais; 2) universalidade dos serviços sociais; e 3) implantação de uma "rede de segurança" de serviços de assistência social. (BEHRING; BOSCHETTI, 2011, p. 94, grifos dos autores).

O plano beveridge ampliou e consolidou outros planos de seguro já existentes, ensejando um modelo de seguro social que padronizou alguns benefícios e incluiu novos, como seguro acidente de trabalho, abono familiar ou salário-família, seguro-desemprego e auxílios sociais, entres eles estão o auxílio-funeral e auxílio-maternidade. Juntos, o modelo bismarckiano e o plano beveridge inspiraram a construção dos sistemas de seguridade social por todo o mundo, oscilando entre a lógica contributiva e a universal.

O declínio das experiências do Estado de Bem-Estar Social ocorre no final da década de 60 , do século passado, corroendo a lógica do pleno emprego, o carro chefe do plano interventivo estatal. Uma nova crise assola o capitalismo e as ideias liberais são reacendidas para defender menor intervenção do Estado na relação capital-trabalho.

As ideias neoliberais produzirão, da década de 70 até a contemporaneidade, políticas sociais focalizadas em segmentos societários, seletivas nas demandas e pontuais na provisão. Parcelas significativas da população que eram assistidas pelas políticas universalistas ficaram desamparadas, pois não se enquadram nos perfis de cidadão alcançados pelas iniciativas de proteção social.

No bojo desses ideais econômicos serão implantados e implementados os sistemas de seguridade social em todo o mundo, inclusive no Brasil. E considerando que se fortalece mais uma vez a responsabilidade individual em garantir condições de sobrevivência 
pelo meio do trabalho (neoliberalismo), são ensejadas novas formas de políticas sociais, destinadas aos pobres e miseráveis, baseadas em ações de caridade e assistencialistas que têm como lógica a solidariedade àqueles que não foram ou são competentes em garantir provisão de suas necessidades básicas com o dispêndio da força de trabalho.

No caso do Brasil, foi somente a partir de 1930 que datam os primeiros registros da assistência pública institucionalizada. Antes disso, o que se tinha no país eram práticas de ajuda que datam do período colonial, executadas pelas ordens religiosas europeias que aqui se instalaram. Do período colonial até uma fase bastante avançada do Império, seguida da República, a assistência estava subsumida à lógica humanitária cristã. (IAMAMOTO; CARVALHO, 2000).

A industrialização brasileira afeta diretamente a classe trabalhadora que começa a crescer e a habitar os centros urbanos, exposta a vários problemas decorrentes da pobreza e da miséria. Nesse processo, o Estado é chamado a intervir junto às demandas de um novo perfil de trabalhador, urbano e industrial, por meio das políticas sociais.

Em 1923, com a Lei Eloy Chaves (Decreto Legislativo $\mathrm{n}^{\circ}$ 4.682, de 24 de janeiro de 1923), são implantadas as Caixas de Aposentadoria e Pensões (CAPs), primeira manifestação do que hoje se constitui a Previdência Social. É na década de 30 que a questão social passa a entrar efetivamente na agenda interventiva do Estado com o ingresso da classe operária no cenário político da sociedade. Nesse período foram criados os Institutos de Aposentadoria e Pensões (IAPs), a Consolidação das Leis Trabalhistas (CLT), o salário mínimo, a valorização da saúde do trabalhador e outras medidas de cunho social, embora de caráter conservador e paternalista.

Para o atendimento das demandas da classe trabalhadora, o Brasil vivenciou o modelo de seguridade tendo como base o modelo bismarckiano, destinado apenas a uma parcela da população, especialmente, aquela que estava inserida no mercado de trabalho. Aos demais, excluídos do processo de produção, cabiam recorrer às casas de caridade. Além disso, o Brasil também um país com forte influência das doutrinas cristãs, terá suas práticas assistenciais alicerçadas nas referências europeias e a Igreja exercerá significativo comando na prestação da assistência aliada ao Estado, atendendo parcela significativa da população que não estava inserida no mercado de 
trabalho, como pessoas idosas, crianças, desempregados e inválidos. (BEHRING; BOSCHETTI, 2011).

Com o Estado Novo (1937-1945), governo instalado por Getúlio Vargas com a justificativa de conter um golpe comunista que assombrava o país, as políticas sociais se desenvolvem significativamente dando respostas às necessidades decorrentes do processo de industrialização. $\mathrm{O}$ inchaço das cidades e a falta de estrutura para receber os trabalhadores exigem do Estado maior incremento na área social, o que o levou a garantir os primeiros direitos sociais. Essas manifestações iniciais de cidadania eram restritas aos trabalhadores formais. Para os trabalhadores pobres sem carteira assinada, ou desempregados, restavam as obras sociais e filantrópicas oriundas da Igreja. Além disso, manifestações contrárias ou que requeressem maior atuação do Estado eram duramente reprimidas, sendo a questão social tratada como caso de polícia. (IAMAMOTO; CARVALHO, 2000).

Vale destacar que em 1938 é criado o Conselho Nacional de Serviço Social (CNSS), responsável pela atenção aos pobres, perdurando até o ano de 1993, sendo um órgão "[...] clientelista e cartorial, objeto de escândalos nacionais, processos de corrupção e subvenções a entidades fantasmas." (YAZBEK, 2004, p.13). E, em 1942, o governo criou a Legião Brasileira de Assistência (LBA) para atender às famílias dos expedicionários brasileiros. Mas, terminada a II Guerra,

[...] a LBA se volta para a Assistência à maternidade e a infância, iniciando a política de convênios com instituições sociais no âmbito da filantropia e da benemerência. Caracterizada por ações paternalistas e de prestação de auxílios emergenciais e paliativos à miséria vai interferir junto aos segmentos mais pobres da sociedade mobilizando a sociedade civil e o trabalho feminino (YAZBEK, 2004, p.91).

No período dos governos militares a questão social continua sendo tratada como caso de polícia. As manifestações trabalhistas eram respondidas com o binômio repressão-assistência. Os direitos sociais não eram implantados como uma conquista, mas concedidos pelo Estado para amainar as contestações de boa parte da sociedade. As políticas sociais desse período foram marcadas pelo clientelismo político, perdurando a segregação entre os trabalhadores formais e os pobres ou desempregados, restando a estes as ações filantrópicas. 
TRAJETORIA DA REGULAMENTAÇÃO DOS BENEFÍCIOS EVENTUAIS:

da previdência ao $S U A S$

\section{ASSISTÊNCIA SOCIAL E MARCO DO SUAS}

Com o processo de redemocratização do país iniciado na década de 80, do século passado, e com o declínio do governo militar e a maior organização dos movimentos sociais, a assistência social ganha um novo viés, caminhando para sua configuração enquanto política pública. Com Carta Constitucional de 1988, ela recebe o caráter da primazia pública, tendo o Estado como o responsável pela sua execução. Logo, a garantia de melhores condições de vida e trabalho passa a ser responsabilidade do Estado, que deverá promovê-las a partir do sistema de seguridade social, ao lado da saúde e da previdência. Mas a garantia no texto constitucional de uma concepção de assistência social não implica, necessariamente, em sua materialização.

Os governos republicanos que sucedem a Constituição Federal de 1988 vivenciaram uma mudança na conjuntura política, econômica e social. Cada novo chefe do poder executivo, a partir de 1988, utilizou-se de estratégias para alavancar a economia e ao mesmo tempo seguir (ou não) o que rege a Constituição no que diz respeito aos direitos sociais. O período que compreende os anos de 1985 e 1999, segundo Couto (2010), e correspondem aos governos de Sarney, Collor, Itamar Franco e Fernando Henrique Cardoso (FHC), houve, na verdade, uma centralização nas políticas econômicas a fim de alcançar a estabilidade nesse setor. Pouco se avançou na efetivação dos direitos conquistados recentemente, uma vez que estava encabeçado um projeto de crescimento em que o Estado pouco intervinha socialmente - neoliberalismo.

No sentido de regulamentar o que está garantido na Constituição, em 1993 foi definida a LOAS (Lei no 8.742), que trouxe as diretrizes para a operacionalização da política de assistência social no âmbito da proteção social. Esta lei provoca uma profunda transformação no cerne da mesma, buscando afastá-la dos antigos modelos de operacionalização caracterizados especialmente pela ausência de planejamento e arraigados de noções de assistencialismo e/ou paternalismo. Segundo Sposati (2004), a LOAS significou uma transformação genética na assistência social que a aproximou dos conceitos de democracia política e social efervescentes na sociedade brasileira. O próprio processo de aprovação dessa lei foi resultado de grande movimentação popular e da pressão do Ministério Público, 
que advertia o governo Itamar Franco acerca de sua negligencia com a área social ${ }^{5}$.

Dá-se início a um caminho desafiador para transpor a assistência social à condição de política pública fiadora de direitos a partir da regulamentação dos arts. 203 e 204 da Constituição de 1988. A aprovação da Política Nacional de Assistência Social (PNAS) 2004 coloca-se como pedra fundamental para a criação do sistema nacional de gestão descentralizada da assistência social, denominado de SUAS.

O processo de construção do sistema se inicia em 2003 com a IV Conferência Nacional de Assistência Social, após 10 anos de aprovação da LOAS. As deliberações ocorridas apontavam para o interesse em avaliar e avançar na materialização das concepções da LOAS, uma vez que a assistência social, nos Estados e municípios brasileiros, estava se constituindo de maneira diversificada ou desconexa das diretrizes e princípios elencados em sua lei orgânica. Daí, a partir da necessidade de padronizar a oferta dos serviços, programas, projetos e benefícios socioassistenciais, é elaborada a PNAS 2004, trazendo clareza para efetivação da assistência social por meio de um sistema, como direito de cidadania e responsabilidade do Estado.

Calcado num modelo de gestão compartilhada e pautado no pacto federativo, onde se definem as atribuições e competências de cada ente federado, é o SUAS que define e organiza elementos importantes para a execução das ações, consolidando princípios, diretrizes e objetivos com direção à proteção social. É um sistema público, independente de contribuição, descentralizado e participativo que tem como função gerir a política pública de assistência social. (BRASIL, 2005).

A PNAS2004 estabelece que as ações socioassistenciais se realizem através de dois níveis de proteção social: PSB e Proteção Social Especial (PSE), que ainda se divide em média ou alta complexidade.Enquanto a PSB refere-se à prevenção de situações de risco e vulnerabilidades sociais e tem os CRAS como equipamen-

\footnotetext{
Vale ressaltar que em 1990 foi editada a primeira versão da LOAS que foi totalmente vetada pelo então presidente, Fernando Collor de Melo, sob alegação que sua estruturação prejudicaria o orçamento público. Segundo Couto $(2010$, p. 146), “[...] em relação ao campo social, o período [de 1990 a 1992] caracterizou-se por mecanismos que incidiram no sistema de proteção social, desmontando-o, principalmente em relação à seguridade social.” A era Collor, colocou em xeque a área social que havia ganhado destaque há pouco com a Constituição e o sistema de proteção social assegurado foi negligenciado.
} 
TRAJETORIA DA REGULAMENTAÇÃO DOS BENEFÍCIOS EVENTUAIS:

da previdência ao $S U A S$

tos principais de operacionalização, a PSE tem sua atenção voltada para situações em que os direitos foram violados, tendo os Centros de Referência Especializados de Assistência Social (CREAS) como equipamento de operacionalização na média complexidade e as instituições ou serviços de acolhimento integral na alta complexidade.

O SUAS versa a organização das ações da política de assistência social em todo o território nacional, tendo como base a hierarquização dos serviços através de níveis de complexidade. Essa estratégia vem no sentido de favorecer uma melhor articulação e organização dos serviços, buscando abandonar o antigo modelo de práticas emergenciais e descontínuas que a caracterizavam como caridade, como o caso da LBA.

A assistência social, portanto, tem seu reconhecimento como política pública operacionalizada por meio de um sistema que visa garantir e assegurar os direitos de cidadania, e abandonar as ações de caridade e assistencialistas que por muitos anos tutelou e cerceou os direitos sociais.

4 DAS AÇÕES SOCIOASSISTENCIAIS: os benefícios eventuais

Até alcançar o caráter de direito social legalmente assegurado, os benefícios eventuais, que hoje compõem a PSB, tiveram uma expressiva trajetória no Brasil que se iniciou pela via da caridade nos primórdios das manifestações da assistência social, configurando-se aquém da concepção de direito. Passando pela Previdência Social, período em que para sua concessão havia a necessidade de prévia contribuição e, por fim, consolida-se elemento constitutivo da política pública de assistência social que pode possibilitar direito de cidadania.

Historicamente, os benefícios eventuais são tipos de resposta às demandas emergenciais da população, notadamente aquela que vivencia as expressões da pobreza e da miséria. Assumem diversas configurações em determinados tempos históricos, direcionados ao caráter imediato da sobrevivência e da reprodução da força de trabalho necessária ao padrão de acumulação do capitalismo.

Em termos contemporâneos há um debate sobre o atendimento dos mínimos sociais previsto na LOAS como direito social, o que não se materializa quando a concepção é restrita, residual, focalista e seletiva. (PEREIRA, 2011). Os mínimos sociais variam de “[...] uma 
parca ração alimentar para matar a fome dos necessitados, uma veste rústica para protegê-los do frio, um abrigo tosco contra as intempéries, um pedaço de terra [...] ou um salário estipulado pelas elites no poder." (PEREIRA, 2011, p. 16, grifos nossos). Essas concepções arraigaram-se nas práticas filantrópicas religiosas e nos interesses dominantes, reproduzindo respostas isoladas, emergenciais e sem efeitos em face das expressões da questão social. A autora propõe o debate de mínimos sociais ao atendimento das necessidades fundamentais humanas por políticas sociais.

De acordo com Pereira (2011), os mínimos sociais variam conforme a concepção de modelo de proteção social, que variam entre o direito e o não direito. De um modo geral, mínimos sociais se vinculam a recursos mínimos destinados a pessoas incapazes de prover sua subsistência através da venda da força de trabalho. "Propor mínimos sociais é estabelecer o patamar de cobertura de riscos e de garantias que uma sociedade quer garantir a todos seus cidadãos. Trata-se de definir o padrão societário de civilidade. Neste sentido ele é universal e incompatível com a seletividade ou focalismo." (SPOSATI, 1997, p. 10).

Pereira (2011) propõe a superação da ideia de conotação de menor, de menos e de infimidade, substituindo-a por algo fundamental, principal, primordial. Sugere a mudança da concepção de mínimo como supressão ou cortes de atendimentos, típica do padrão liberal, para a ideia de básico essencial para o alcance do direito. A LOAS (1993) normativamente prevê os mínimos sociais a fim de garantir o atendimento das necessidades básicas e os benefícios eventuais são uma modalidade primordial para atendimento das necessidades básicas.

A partir da LOAS, a destinação de provisão para atendimento das necessidades humanas básicas ${ }^{6}$ tomou a concepção de direito e entrou na agenda política devendo ser dever do Estado. Contudo, apenas com a PNAS (2004) e a criação do SUAS (2005), os benefícios eventuais passam a ter essa diretriz em sua forma de concessão, estando localizado na Proteção Social Básica, que atua na prevenção de risco e vulnerabilidade social dos cidadãos e suas famílias.

\footnotetext{
${ }^{6}$ Corroboramos com o entendimento de Pereira (2011) sobre as necessidades humanas básicas em que se pressupõe condição previa suficiente para o exercício da cidadania; ou seja: que o sujeito tenha condições tanto de produzir quanto de reproduzir-se socialmente.
} 
Entendendo eventual como sinônimo, também, de contingência, em que algo e/ou uma situação pode ocorrer, os benefícios eventuais devem atender as necessidades decorrentes das eventualidades a que os cidadãos são passiveis de ocorrência. (PEREIRA, 2010).

A primeira menção legal dos benefícios eventuais data de 1954, a partir do Decreto no $35.448 / 1954$, promulgado por Getúlio Vargas, que trazia o Regulamento Geral dos IAPs. O conteúdo tratava os benefícios como auxílios, sejam para a maternidade ou funeral, únicos reconhecidos enquanto direito dos segurados e que, portanto, estavam subordinados ao vínculo previdenciário-trabalhista. Sua forma de oferta se dava por meio do pagamento de um salário mínimo vigente e possuía o período de carência de doze meses. (BOVOLENTA, 2011).

Em 1960, com a instituição da Lei Orgânica da Previdência Social (LOPS), houve a segunda menção sobre os benefícios, mantendo-se inalterados até então. Além da mudança de nomenclatura de auxilio maternidade para natalidade, houve ampliação de acesso ao considerar outros dependentes do segurado - esposa, filha, irmã maior de idade, solteira, desquitada ou viúva - para alguém designado pelo segurado que comprovasse viver sob sua dependência econômica. Já o auxílio funeral passou de um para dois salários mínimos, destinados para os dependentes do segurado falecido ou a outrem que comprovasse o custeio do funeral. (BOVOLENTA, 2011).

A LOPS previa a unificação dos institutos de aposentadoria e a padronização dos benefícios previdenciários concedidos. Contudo, somente em 1966, com o Decreto-Lei ${ }^{\circ} 72$, de 21 de novembro, foi possível administrá-los de modo unificado e, com isso, ampliar o acesso aos benefícios, mesmo que ainda pautada na lógica do seguro, deixando todos os não segurados desassistidos de provisão.

Não havendo nada legalmente instituído, cabia à LBA o fornecimento de algum benefício à gestante pobre, como enxoval para o bebê, e a urna funerária ao falecido cuja família não dispusesse de meios para custeio da morte.Por mais de duas décadas ficaram assim configurados os benefícios assistenciais, tanto para os segurados que eram providos pela previdência, e os não segurados, que dependiam da solidariedade privada e/ou religiosa.

A partir da década de 90 houve grande crise na economia que ensejou a redução dos gastos sociais com o fito de recuperar o con- 
trole sobre a inflação e barrar a queda no crescimento. O que não foi diferente no Brasil. Em 1991, com a Lei n ${ }^{\circ} 8.213$, de 24 de julho, que descrevia os Planos de Benefícios da Previdência, foi salientado o princípio de seletividade através do corte de renda no bojo de um ideal de universalidade de acesso, mesmo que calcado na lógica do seguro.

As mudanças trazidas selecionavam como perfil de acesso aqueles com renda menor que três salários mínimos, no caso do auxílio natalidade, além da redução do valor de um salário mínimo para uma cota única - de valor inferior a $30 \%$ do salário mínimo vigente - mesmo que tanto o pai e a mãe fossem segurados. O auxílio funeral também teve seu valor reduzido, de dois para um salário mínimo, com a seleção baseada no corte de renda de, também, inferior a três salários.

Nesse período já tomava corpo a discussão e o próprio processo de transição dos benefícios da alçada da previdência para responsabilidade da assistência social, o que Pereira (2010) salienta nesse processo de transição a partir da crítica com relação à redução de seus valores e da restrição do acesso (seletividade).

Com o neoliberalismo também influenciando as ações estatais no Brasil, houve redução dos gastos sociais e dos valores dos benefícios, levando a adoção do princípio da seletividade. Em relação aos benefícios eventuais, esses foram sendo achatados desde que foi se tornando claro sua transição entre as políticas de seguridade. Fato esse em que cabe a discussão sobre a concepção que se tem da Assistência Social, onde o valor do benefício é diminuído sem qualquer esclarecimento que fundamente tal redução. (BOVOLENTA, 2011).

A LOAS consolidou a transição dos benefícios eventuais. Em sua primeira versão (1993), apresentou os benefícios eventuais como "[...] aqueles que visam ao pagamento de auxilio por natalidade ou morte às famílias cuja renda mensal per capita seja inferior a 1/4 (um quarto) do salário mínimo." (BRASIL, 1993, art. 22). Além disso, estabelece outros benefícios para o atendimento de necessidades ocorridas por situações de vulnerabilidade temporária e casos de calamidade pública.Quanto à previdência, esta deixou de concedê-los sem qualquer justificativa ou ressarcimento àqueles trabalhadores que já haviam contribuído para tal. 
TRAJETORIA DA REGULAMENTAÇÃO DOS BENEFÍCIOS EVENTUAIS:

da previdência ao $S U A S$

Com a LOAS não houve apenas mudança de nomenclatura - passando de auxílios para benefícios - mas, também, redução e desconstrução destas provisões ao se estabelecerem na política de assistência social. Mesmo que já viessem sofrendo redução em sua última legislação ainda na previdência, quando o valor do auxílio natalidade reduziu de um salário mínimo para uma cota única inferior a $30 \%$ do mesmo, e o auxílio funeral de dois passou para um salário, na assistência social estes se tornaram ainda mais focalizados numa parcela da população cuja renda per capita deve ser inferior a $1 / 4$ do salário mínimo (mesmo superando este critério a partir de 2011, com a Lei no 12.435, de 6 de julho).

Outra questão trazida com a LOAS foi a responsabilização dos Conselhos de Assistência Social em suas respectivas esferas Municípios, Estados e Distrito Federal - pela regulação dos benefícios, passando os municípios a serem os responsáveis pela definição dos benefícios eventuais conforme sua realidade local.

Com reconhecimento dos benefícios como responsabilidade da assistência social, houve avanço por concebê-los como direito de cidadania para famílias e indivíduos que vivenciam situações de vulnerabilidade social, sem necessidade de prévia contribuição. Por sua proximidade espacial com seus demandantes, os benefícios eventuais, caracterizados pela eventualidade de sua ocorrência e pela urgência de seu atendimento, ficaram na alçada dos municípios. Mesmo assim, em função da regulamentação local (via Conselho Municipal de Assistência Social [CMAS] e da própria prefeitura), perduraram critérios de acesso à base da lógica per capita, reproduzindo seu caráter seletivista. A grande maioria dos governos municipais não se sente equipada financeiramente para arcar com esse instrumento de proteção social.

Ao mesmo tempo em que a municipalização dos benefícios tende a contribuir na sua organização/operacionalização na perspectiva do direito, esta mesma condição os torna reféns do financiamento municipal que, geralmente, não arrecada o suficiente para ofertá-los. Ainda a grande realidade em que os Estados não garantem para todos os Municípios o cofinanciamento dos benefícios eventuais, como preconiza a LOAS (informação constata em estudo encomendado pelo Conselho Federal de Serviço Social [CFESS] que será citado logo mais adiante). 
Mas não foi apenas a condição financeira desses entes federados que impossibilitou a regulamentação dos benefícios como indicou a LOAS. Houve uma série de dificuldades de entendimento dos conceitos presentes na lei ou de consenso na definição das provisões, bem como permaneceu o caráter seletivista dos mesmos através do critério de acesso aos benefícios por meio da per capita semelhante ao Benefício de Prestação Continuada (BPC).

Pereira (2010) destaca algumas avarias decorrentes da ausência de regulamentação: a) tornou a legislação preexistente em letra morta haja vista que sua disposição na LOAS carece de regulamentação específica para tornar possível sua implementação; b) ao passar para alçada da assistência social, os benefícios foram automaticamente suspensos da previdência; portanto, deixou de atender devidamente não só os beneficiários dentro da assistência social, quanto os cidadãos antes contemplados por seu vínculo previdenciário; c) induziu focalização na extrema pobreza, parcela da população com renda per capita inferior a $1 / 4$ do salário mínimo; d) incentivou práticas clientelistas e assistencialistas, e; e) ausência de tratamento particular dos benefícios no âmbito da assistência social havendo inconsistência no entendimento do que seria a alçada desta política pública e das demais.

Não obstante, o Conselho Nacional de Assistência Social (CNAS) realizou alguns intentos para consolidar os benefícios eventuais na condição de direitos. O primeiro deles foi uma pesquisa diagnóstica sobre a situação legal dos benefícios eventuais, no ano de 1996, encomendada pelo CFESS. A partir desse levantamento, foi possível identificar as principais vicissitudes no reconhecimento teórico, conceitual, político, cultural e ético que permeiam a operacionalização desses benefícios.

Em 2004, o Ministério do Desenvolvimento Social e Combate à Fome (MDS) solicitou o desenvolvimento de nova pesquisa sobre a situação dos benefícios eventuais, em que participaram 626 Municípios de 11 Estados. Cerca de mais de 10 anos após a LOAS, os Municípios não haviam claramente definido os critérios e forma de concessão dos benefícios eventuais. A pesquisa ainda destacou o reincidente assistencialismo em torno das concessões, que variava entre a "[...] distribuição de cestas básicas, filtros, leite, cadeiras de rodas, órteses, próteses dentarias, óculos, roupas, fraldas geriátricas, auxilio funeral; doação de passagens rodoviárias, de material de 
TRAJETORIA DA REGULAMENTAÇÃO DOS BENEFÍCIOS EVENTUAIS: da previdência ao $S U A S$

construção; e fornecimentos de medicamentos." (PEREIRA, 2010, p. 23-24).

Considerando o resultado da pesquisa, o CNAS promulgou a Resolução $\mathrm{n}^{\circ} 212$, de 19 de outubro de 2006, que propõe critérios orientadores para regulamentação da provisão de benefícios eventuais no âmbito da assistência social. Em seu texto, a resolução traz a definição desses benefícios, seus destinatários, as competências dos entes federados, incluindo o cofinanciamento, e o papel dos Conselhos de Assistência Social.

Em 2007 foi promulgado o Decreto $\mathrm{n}^{\circ}$ 6.307, de 14 de dezembro, que regulamentou os benefícios eventuais. Inova ao tratar da situação de vulnerabilidade temporária e de calamidade pública, e ao definir que as provisões relativas a programas, projetos, serviços e benefícios diretamente vinculados ao campo da saúde, educação, integração nacional e demais políticas setoriais que não se incluem nos termos de benefícios eventuais da assistência social.

No ano de 2009, cerca de 1.229 municípios tiveram os benefícios eventuais regulamentados com base nos parâmetros dispostos nestas legislações (PEREIRA, 2010). Convém ressaltar, porém, que as dificuldades de cofinanciamento perduraram (e perduram), uma vez que esses entes federados apresentam insuficiência de recursos, notadamente irrisórios frente às demandas. Nesse novo levantamento para averiguação da situação da regulamentação dos benefícios eventuais nos municípios foi constatado significativo avanço.

Neste mesmo ano, com intento de fortalecer a função protetiva das famílias e entendendo que a superação de vulnerabilidades e riscos sociais supera a dimensão da renda, a Comissão Intergestora Tripartite (CIT) promulgou a Resolução $\mathrm{n}^{\circ}$ 7, de 10 de setembro de 2009, que define o Protocolo de Gestão Integrada de Serviços, Benefícios e Transferências de Renda no âmbito do SUAS. Nesse documento, há reconhecimento dos benefícios eventuais como integrantes do SUAS e que sua prestação deve atender o princípio da integração à rede de serviços socioassistenciais, com vistas ao atendimento das necessidades humanas básicas.

O SUAS define os benefícios eventuais como provisões ofertadas em espécie ou pecúnia que tem por objetivo cobrir determinadas necessidades temporárias, em razão de contingências relacionadas a situações de vulnerabilidade temporária em decorrência 
do ciclo de vida, situações de desvantagem pessoal ou a ocorrência de incertezas que representam perdas e danos. Contudo, conforme destacamos anteriormente, o reconhecimento legal dos benefícios eventuais como direito não foi suficiente para os implementar como tal. Por vários motivos, que variam entre a insuficiência de recursos municipais, a dificuldades de definição das modalidades para atendimento das demandas da população, a regulamentação desses benefícios foi subsumida, prejudicando a garantia de atendimento das necessidades humanas básicas de seus demandantes

\section{CONCLUSÃO}

É possível perceber a intenção de ruptura com ações improvisadas ou distanciadas da concepção de direito para concessão dos benefícios eventuais. São requisitados estudos, diagnósticos, mapeamentos da realidade, dos beneficiários e das demandas para que as provisões sejam asseguradas com rapidez e presteza.

Após seis anos de SUAS, o Sistema é organizado legalmente através da Lei $\mathrm{n}^{\circ} 12.435 / 2011$, que atualizou a LOAS às suas exigências. Foi assegurado em lei a competência dos Estados em destinar recursos financeiros aos Municípios para o cofinanciamento dos benefícios eventuais. Aos municípios, compete tanto a destinação de recursos como definição de critérios, isto é, sua regulamentação através dos Conselhos Municipais, como enfatiza a obrigatoriedade do pagamento de duas modalidades: o auxílio natalidade e funeral, classificados como compulsórios, por Pereira (2010).

De ações com caráter assistencialista, patrimonialista e por vezes tuteladoras, os benefícios eventuais se configuram atualmente como provisões que integram um sistema que efetiva uma política pública organizada hierarquicamente através de níveis de proteção, que tem por objetivo prevenir situações de vulnerabilidade ou risco social e/ou o enfrentamento das situações de violação de direitos. Devem ser concedidos, portanto, para a garantia da segurança dos usuários da política que vivenciam situação de contingência social entre o nascimento, morte, vulnerabilidade ou em situação de calamidade.

De 1953 até 2011 os benefícios eventuais tiveram, e ainda têm no Brasil, trajetória conturbada, passando da responsabilidade de uma política para outra; mudando de nomenclatura; de modalidades de provisão ou indefinição destas; de público alvo; condições 
TRAJETORIA DA REGULAMENTAÇÃO DOS BENEFÍCIOS EVENTUAIS:

da previdência ao $S U A S$

de acesso; de valores, e com insuficiência de financiamento.Porém, desde 2011, adquiriram reconhecimento legal e foram instituídos enquanto provisões suplementares e provisórias que integram organicamente as garantias do SUAS.

Os benefícios eventuais, de caráter socioassistencial, têm como finalidade assegurar que seus usuários tenham condições humanas básicas de gozar de seus direitos. Pois, conforme salienta Pereira (2011), são as aquisições de bens, serviços e direitos, a partir do estabelecimento de provisões básicas, que propiciam aos indivíduos capacidade de escolha e decisão, de questionar suas formas de vida e cultura, bem como lutar pela sua melhoria ou mudança.

A atual configuração legal dos benefícios eventuais se direciona para garantir provisões básicas, dentro de um sistema organizado hierarquicamente que entende que as vulnerabilidades e riscos sociais a que as famílias estão propensas a ser vitimadas, superam a questão da renda - mesmo que em boa parte dos municípios este critério ainda esteja presente.

Devem ser planejados, definidos e providos com presteza e eficiência para atender as contingências sociais e devem superar o improviso e indefinição que os marcaram por mais de dez anos com a falta de regulamentação municipal. Por fim, devem assegurar que os indivíduos e suas famílias reconheçam-se enquanto ser de direitos de acesso a estas provisões como forma de superação de vulnerabilidades temporárias vivenciadas.

Contudo, mesmo com todo o aparato legal para garantir as deliberações dos Conselhos Municipais na regulamentação dos benefícios eventuais, em muitos municípios ainda perdura o caráter seletivo na definição do público de acesso, adotando o corte de renda per capita familiar inferior a $1 / 4$ do salário mínimo, seja por falta do entendimento que há possibilidade de ampliação, ou seja para focalizar o público e, assim, custear menos provisões em virtude da insuficiência de recurso municipal agravada pela ausência do cofinanciamento estadual. Os Estados, por sua vez, não conseguem suprir a necessidade de participação no custeio de todos seus municípios, já que a demanda é elevada frente à fonte de recursos.

O caráter seletivo ainda assola a definição e a concessão dos benefícios eventuais. Permeia a seletividade na concessão e a destinação dos recursos públicos para seu cofinanciamento ainda é muito 
tímida. O que nega os direitos sociais. É tendência da política econômica neoliberal subjugar os gastos com o social para o fortalecimento da economia. E por mais que se tenha avançado no reconhecimento dos direitos de cidadania, estes ainda ficarão à mercê da política dessa lógica excludente. Avancemos noutras perspectivas.

\section{REFERENCIAS}

BEHRING, E. R.; BOSCHETTI, I. Política Social: fundamentos e história. 9. ed. São Paulo: Cortez, 2011. (Biblioteca Básica do Serviço Social, v. 2).

BOSCHETTI, I. A política da seguridade social no Brasil. In: CONSLEHO FEDERAL DE SERVIÇO SOCIAL; ASSOCIAÇÃO BRASILEIRA DE ENSINO E PESQUISA EM SERVIÇO SOCIAL. Serviço Social: direitos sociais e competências profissionais. Brasília, DF: CFESS/ABEPSS/CEAD-UNB, 2009.

BOVOLENTA. G. A. Os benefícios eventuais previstos na Loas: o que são e como estão. Serviço Social e Sociedade, São Paulo, n. 106, p. 365-387, abr./jun. 2011.

BRASIL. Presidência da República. Lei $n^{\circ}$ 8.742, de 07 de Dezembro de 1993. Lei Orgânica da Assistência Social. Dispõe sobre a organização da Assistência Social e dá outras providências. Diário Oficial da União, Brasília, DF, 1993. Mimeo.

. Ministério do Desenvolvimento Social e Combate à Fome. Política Nacional de Assistência Social (PNAS 2004) e Norma Operacional Básica (NOB/SUAS 2005). Brasília, DF, 2005.

COUTO, B. R. O direito social e a assistência social na sociedade brasileira: uma equação possível? 4. ed. São Paulo: Cortez, 2010.

IAMAMOTO, M. V.; CARVALHO, R. Relações Sociais e Serviço Social no Brasil: esboço de uma interpretação histórico-metodológica. 20. ed. São Paulo: Cortez, 2000.

PEREIRA, P. A. Necessidades humanas: subsídios à crítica dos mínimos sociais. 6. ed. São Paulo: Cortez, 2011.

. Panorama do processo de regulamentação e operacionalização dos benefícios eventuais regidos pela Loas. Cadernos de Estudos Desenvolvimento Social em Debate, Brasília, DF, n. 12, p. 11-30, 2010.

SANTOS, J. S. Questão social: particularidades no Brasil. São Paulo: Cortez, 2012. (Biblioteca Básica de Serviço Social). 
TRAJETORIA DA REGULAMENTAÇÃO DOS BENEFÍCIOS EVENTUAIS: da previdência ao SUAS

SPOSATI, A. de O. A menina Loas: um processo de construção da assistência social. São Paulo: Cortez, 2004.

. Mínimos sociais e seguridade social: uma revolução da consciência da cidadania. Serviço Social e Sociedade, São Paulo, ano 18, n. 55, p. 9-38, nov. 1997.

YAZBEK, M. C. As ambiguidades da assistência social brasileira após dez anos de LOAS. Serviço Social e Sociedade, São Paulo, ano 25, n. 77, mar. 2004. 
